\title{
Transcriptomic signatures of transfer cells in early developing nematode feeding cells of Arabidopsis focused on auxin and ethylene signaling
}

\author{
Javier Cabrera, Marta Barcala, Carmen Fenoll and Carolina Escobar* \\ Laboratory of Plant Physiology, Department of Environmental Sciences, Facultad de Ciencias Ambientales y Bioquímica, Universidad de Castilla-La Mancha, Toledo, \\ Spain
}

\section{Edited by:}

Gregorio Hueros, Universidad de Alcalá, Spain

\section{Reviewed by:}

Uener Kolukisaoglu, University of Tuebingen, Germany

Vasileios Fotopoulos, Cyprus

University of Technology, Cyprus

\section{*Correspondence:}

Carolina Escobar, Laboratory of

Plant Physiology, Department of

Environmental Sciences, Facultad

de Ciencias Ambientales y

Bioquímica, Universidad de

Castilla-La Mancha, Avenida de

Carlos III s/n, 45071 Toledo, Spain

e-mail: carolina.escobar@uclm.es

Phyto-endoparasitic nematodes induce specialized feeding cells (NFCs) in their hosts, termed syncytia and giant cells (GCs) for cyst and root-knot nematodes (RKNs), respectively. They differ in their ontogeny and global transcriptional signatures, but both develop cell wall ingrowths $(\mathrm{Cls})$ to facilitate high rates of apoplastic/symplastic solute exchange showing transfer cell (TC) characteristics. Regulatory signals for TC differentiation are not still well-known. The two-component signaling system (2CS) and reactive oxygen species are proposed as inductors of TC identity, while, 2CSs-related genes are not major contributors to differential gene expression in early developing NFCs. Transcriptomic and functional studies have assigned a major role to auxin and ethylene as regulatory signals on early developing TCs. Genes encoding proteins with similar functions expressed in both early developing NFCs and typical TCs are putatively involved in upstream or downstream responses mediated by auxin and ethylene. Yet, no function directly associated to the TCs identity of NFCs, such as the formation of $\mathrm{Cls}$ is described for most of them. Thus, we reviewed similarities between transcriptional changes observed during the early stages of NFCs formation and those described during differentiation of TCs to hypothesize about putative signals leading to TC-like differentiation of NFCs with particular emphasis on auxin an ethylene.

Keywords: plant-nematode interaction, giant cells, early transcriptomic signatures, syncytia, auxin, ethylene, transfer cells, cell wall ingrowths

\section{INTRODUCTION}

Phyto-endoparasitic nematodes interact with their hosts in a subtle manner. They induce cells from the vascular cylinder to differentiate into specialized feeding cells (NFCs), syncytia, and giant cells (GCs), the nourishing cells for cyst and root-knot nematodes (RKNs), respectively (Jones and Goto, 2011; Sobczak and Golinowski, 2011). Although these two cell types clearly differ in their ontogeny, both develop cell wall ingrowths (CIs) believed to facilitate high rates of apoplastic/symplastic solute exchange typical of transfer cells (TCs; Jones and Dropkin, 1976; Siddique et al., 2012). In GCs the amplification of the plasma membrane surface area could be up to 20 fold (reviewed in Jones and Goto, 2011). CIs are less abundant in male-induced syncytia, suggesting a control probably associated with lower nutrient demand as the development of males inside the plant ends at the J3 stage (reviewed in Sobczak and Golinowski, 2009). Young syncytia are symplastically isolated, although this is lost at later stages (10-15 days post-infection, dpi; Hofmann et al., 2007) and symplastic isolation of GCs is under discussion (Hoth et al., 2008; Hofmann et al., 2010). Thus, amplification of plasma membrane area might be crucial for efficient apoplastic exchange at certain NFC developing stages. Polarized deposition of a thickened wall would need cell signals leading to this specialized differentiation. Those putative signals are still uncertain. Yet, some of the genes described to change their expression during TC differentiation participate in downstream cascades for gene expression driven by ethylene and auxin in epidermal cells of Vicia faba (Dibley et al., 2009) or in barley endosperm (Thiel et al., 2008, 2012a). In addition, genes involved in the biosynthesis of hormones such as auxin, ethylene jasmonic acid, brassinosteroids, gibberellins, and abscisic acid in maize basal endosperm (Xiong et al., 2011) are also differentially expressed in TCs.

Global transcriptomic changes of laser micro-dissected GCs at early developing stages (3 dpi; Barcala et al., 2010) and of micro-aspirated young syncytia (5 dpi; Szakasits et al., 2009) in Arabidopsis indicated that only 529 genes out of 1161 in GCs and 7225 in syncytia (representing 45.5 and $7.3 \%$ of the differentially expressed genes in each transcriptome, respectively) are shared. This indicates that transcriptomic similarities are not high between both nematode-induced cell types. However, key changes in the expression of genes related to several hormones such as auxin, ethylene, jasmonic acid, or abscisic acid are shared between both NFCs (Cabrera et al., 2013).

Only some data on TC regulatory signals in NFCs have been described, i.e., $Z m M R P-1$ codes for a primary sensor of the putative signals for TCs and the activity of this TC-specific promoter ZmMRP-1 (Gomez et al., 2002) was monitored in Arabidopsis transgenic plants; GUS activity was detected in the feeding sites induced by Meloidogyne javanica. Those are swollen parts of the roots (galls) where GCs are embedded surrounded 
by heterogeneous tissues. Although gall microscopy sections were not examined, the confined GUS activity observed suggests that the promoter is probably active in GCs (Barrero et al., 2009). Further research will elucidate whether this TC-specific molecular signature is also present in syncytia formed by cyst nematodes. In order to unveil some clues on putative signals leading to TC-like differentiation of NFCs, we review similarities between transcriptional changes observed during the early stages of NFCs formation and those described during differentiation of TCs. Global gene expression studies comparing syncytia and GCs to TCs signatures could be a starting point to find some answers.

\section{AUXIN AND ETHYLENE AS PUTATIVE SIGNALS INITIATING TC-LIKE MORPHOLOGY OF NFCs}

During the last few years, several transcriptomic studies on early developing TCs have assigned a major role to hormone regulation on the processes leading to the differentiation of these cell types. Auxin (Dibley et al., 2009) and ethylene (Thiel et al., 2008, 2012a,b; Dibley et al., 2009; Zhou et al., 2010; Xiong et al., 2011) raised as the two major phytohormones implicated in the differentiation of TCs from different plants and tissues. In adaxial epidermal cells of cultured $V$. faba cotyledons transdifferentiating to TCs, auxin and ethylene cis-responsive elements were over-represented in the promoters of induced genes. There is a clear functional demonstration that both hormones regulate CI formation in V. faba epidermis, based mainly in pharmacological experiments, indicating their participation in the signaling events leading to TCs differentiation (Dibley et al., 2009; Zhou et al., 2010). Moreover, an increase in auxin and ethylene levels boosts TC formation in tomato roots (Schikora and Schmidt, 2002). Accordingly, a clear over-representation of auxin-regulated genes among the 310 up-regulated genes in Arabidopsis 3 dpi GCs, relative to the total number of hormone responsive genes described in Nemhauser et al. (2006), was observed (Cabrera et al., 2013). Among those upstream genes regulated by auxin are genes in the $A U X / I A A$ group, as IAA8 (Table 1). Genes in this category were also induced in the transcriptome of $V$. faba developing TCs, such as GH1 (Dibley et al., 2009). The development of Heterodera shachtii, a syncytia-forming nematode, was impaired in the axr2 mutant, that also corresponds to the IAA group member IAA7 (Goverse et al., 2000), and IAA26 is induced in the transcriptome of 5 dpi microaspirated syncytia (Table 1; Szakasits et al., 2009). AUX/IAA proteins function by interacting with auxin responsive factors (ARFs) that were also induced in GCs, like MONOPTEROS (MP; ARF5) or ARF19 (Table 1). In syncytia, $A R F 4$ and $A R F 6$ are up-regulated, but not co-regulated with GCs. ARF4 has been defined to be preferentially expressed in the phloem companion cells of Arabidopsis (Table 1; Brady et al., 2007), the TCs found in loading and unloading areas of vascular tissues. Therefore, ARFs are induced in both NFCs triggered by cyst and RKNs at early infection stages, although different family members are involved in each NFC type. Strikingly, 20\% of the genes defined by Brady et al. (2007) as preferentially expressed in the companion cells of Arabidopsis are also up-regulated in syncytia (44 out of 222 genes; Cabrera et al., 2013).

Other genes in the TCs induced in the epidermis of $V$. faba include those that could alter auxin transport through PINs relocalization or enhanced biosynthesis, as nitrilases (Dibley et al., 2009), proposed to alter the pattern of auxin redistribution to drive CI formation. Redistribution of PINs and reduction of nematode reproduction in PIN-related mutants such as pin2, pin3, pin4, pin7, and several double mutants, together with pharmacological treatments with inhibitors of auxin transport, demonstrated that cyst nematodes are able to hijack the auxin distribution network (Grunewald et al., 2009). Similarly, the nematode effectors $\mathrm{Hg} 19 \mathrm{C07}$ and $\mathrm{Hs} 19 \mathrm{CO} 07$ of $\mathrm{H}$. glycines and $H$. schachtii directly interact with the auxin influx transporter LAX3 and infectivity in aux1/lax3 double mutants was severely affected (Lee et al., 2011). Interpretations pointed as a process to facilitate the infection and establishment of nematodes during early stages of the plant-nematode interaction. However, the ability of CIs formation that lead to the TCs nature of NFCs, have not been ever studied in those mutants. Thus, further research with loss of function mutants will be needed to characterize auxin signaling pathways involved in TC character of syncytia and GCs.

Other downstream auxin responsive genes up-regulated in GCs are WES1 and GH3 (Table 1). In syncytia, there is also the GH3-like, DFL1 that regulates lateral root formation through the auxin signaling pathway (Table 1; Nakazawa et al., 2001). The synthetic promoter DR5, derived from the GH3 promoter, has been extensively used to check early increases in local auxin also in NFCs (Karczmarek et al., 2004). It is interesting to point that DR5::GUS expression is located in the GCs and vascular surrounding tissues (Cabrera et al., unpublished results). This suggests that auxin concentration is very high at early infection stages in GCs as compared to the rest of the gall tissues. There are several hypotheses to explain this local increase in auxin levels, i.e., the presence of auxins in the nematode secretions (De Meutter et al., 2005), or the manipulation of auxin homeostasis through the interaction of nematode effectors as chorismate mutase with the plant biochemical machinery (Jones et al., 2003). Interestingly, local production of isoflavonoids could also result in a local auxin increase as they inhibit polar auxin transport. Promoters of genes encoding chalcone synthases involved in the first step of flavonoid biosynthesis are induced in galls of clover (Grunewald et al., 2009), and genes in the category of flavonoid metabolism were induced in syncytia (Cabrera et al., 2013). However, several Arabidopsis mutants impaired in isoflavonoid biosynthesis were not affected in either syncytia or GCs formation (Jones et al., 2007; Wasson et al., 2009). These studies indicate that it is unlikely that flavonoids mediate changes in auxin transport needed for nematode feeding site organogenesis, although galls of Medicago truncatula flavonoid-deficient roots were shorter (Wasson et al., 2009). These findings suggest that the local flavonoid increase encountered in galls (Hutangura et al., 1999; Wasson et al., 2009) might have an alternative role not directly related to the process of infection and establishment. Perhaps flavonoids are related to CI formation needed for the acquisition of TCs characteristics, as suggested by Dibley et al. (2009) in TCs from epidermal cells of $V$. faba. This is another open question that deserves further investigation.

During differentiation of TCs in the endosperm of barley (Thiel et al., 2012a) or trans-differentiation of epidermal cells in 
Table 1 | Genes induced in the $3 \mathrm{dpi} \mathrm{GCs}$ and 5 dpi syncytia transcriptomes (Szakasits et al., 2009; Barcala et al., 2010), that are also described to be regulated by auxin and/or ethylene in Nemhauser et al. (2006) and in Mapman (Thimm et al., 2004).

\begin{tabular}{|c|c|c|c|}
\hline \multicolumn{4}{|r|}{ Syncytia 5 dpi } \\
\hline \multicolumn{4}{|l|}{ CELL } \\
\hline AT1G10740 & IAA & 1.0 & Unknown protein \\
\hline \multicolumn{4}{|l|}{ CELL WALL } \\
\hline AT1G53840 & IAA & 2.1 & PME1: encodes a pectin methylesterase \\
\hline AT5G06860 & IAA & 3.4 & PGIP1: Encodes a polygalacturonase-inhibiting protein involved in defense response \\
\hline AT5G57560 & IAA & 4.4 & TCH4: Encodes a cell wall-modifying enzyme \\
\hline AT5G66460 & IAA & 3.1 & MAN7: (1-4)-beta-mannan endohydrolase \\
\hline \multicolumn{4}{|c|}{ DEVELOPMENT } \\
\hline AT5G57390 & ACC & 1.1 & AIL5: Encodes a member of the AP2 family of transcriptional regulators \\
\hline AT3G16050 & $\mathrm{ACC}$ & 2.0 & PDX1.2: Encodes a protein with pyridoxal phosphate synthase activity \\
\hline AT3G58680 & $\mathrm{ACC}$ & 1.6 & MBF1B: One of three genes in $A$. thaliana encoding multiprotein-bridging factor 1 \\
\hline AT4G26200 & $\mathrm{ACC}$ & 1.2 & ACS7: Member of a family of proteins in Arabidopsis that encode ACC synthase \\
\hline AT4G34410 & ACC & 1.5 & RRTF1: encodes a member of the ERF (ethylene response factor) subfamily B-3 \\
\hline AT5G20550 & $\mathrm{ACC}$ & 1.7 & Oxidoreductase, 2OG-Fe(II) oxygenase family protein \\
\hline AT5G43440 & $\mathrm{ACC}$ & 1.3 & Encodes a protein whose sequence is similar to ACC oxidase \\
\hline AT5G43450 & $\begin{array}{l}\text { ACC } \\
\text { IAA }\end{array}$ & 1.2 & Encodes a protein whose sequence is similar to ACC oxidase \\
\hline AT1G17350 & IAA & 3.3 & Auxin-induced-related/indole-3-acetic acid induced-related \\
\hline AT1G50580 & IAA & 1.5 & Glycosyltransferase family protein \\
\hline AT1G56150 & IAA & 3.1 & Auxin-responsive family protein \\
\hline AT4G12410 & IAA & 2.8 & Auxin-responsive family protein \\
\hline AT4G12980 & IAA & 0.7 & Auxin-responsive protein \\
\hline AT4G27450 & IAA & 1.1 & Unknown protein \\
\hline AT4G34760 & IAA & 1.5 & Auxin-responsive family protein \\
\hline AT5G20810 & IAA & 0.4 & Auxin-responsive protein \\
\hline AT5G54510 & IAA & 2.7 & DFL1: Encodes an IAA-amido synthase that conjugates Ala, Asp, Phe, and Trp to auxin \\
\hline AT5G55540 & IAA & 0.8 & TRN1: Encodes a large plant-specific protein of unknown function \\
\hline AT5G64600 & IAA & 2.3 & Unknown protein \\
\hline \multicolumn{4}{|c|}{ METAL HANDLING } \\
\hline AT2G37330 & IAA & 1.3 & ALS3: Encodes an ABC transporter-like protein \\
\hline \multicolumn{4}{|c|}{ MISCELLANEA } \\
\hline AT2G29440 & $\mathrm{ACC}$ & 1.7 & GSTU6: Encodes glutathione transferase belonging to the tau class of GSTs \\
\hline AT3G11210 & $\begin{array}{l}\text { ACC, } \\
\text { IAA }\end{array}$ & 1.2 & GDSL-motif lipase/hydrolase family protein \\
\hline AT1G30760 & IAA & 6.2 & FAD-binding domain-containing protein \\
\hline AT2G30140 & IAA & 2.8 & UGT87A2: UDP-glucoronosyl/UDP-glucosyl transferase family protein \\
\hline AT3G11210 & IAA & 1.2 & GDSL-motif lipase/hydrolase family protein \\
\hline
\end{tabular}


Table 1 | Continued

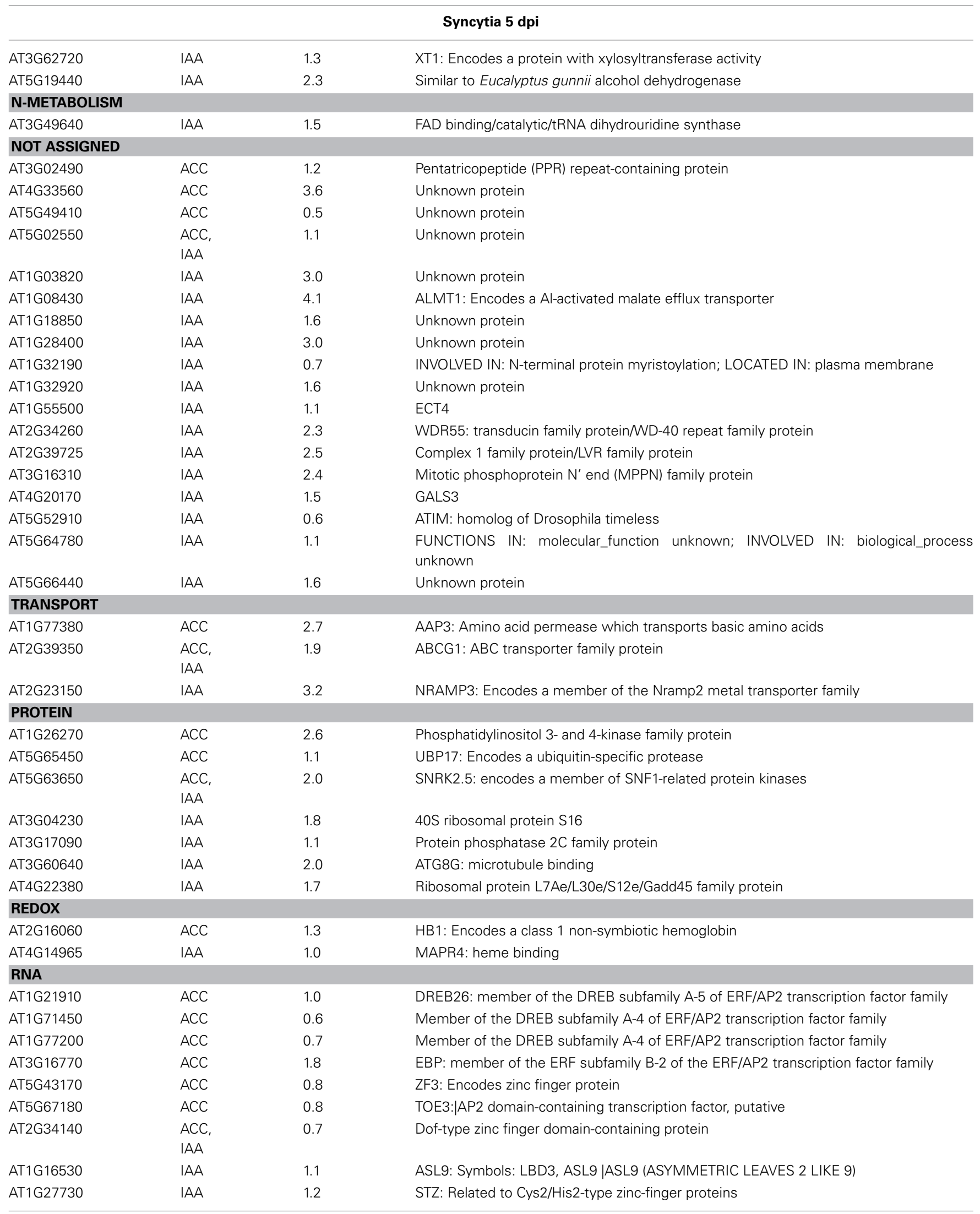


Table 1 | Continued

\begin{tabular}{|c|c|c|c|}
\hline \multicolumn{4}{|r|}{ Syncytia 5 dpi } \\
\hline AT1G30330 & IAA & 0.9 & ARF6: Mediates auxin response via expression of auxin-regulated genes \\
\hline AT2G33860 & IAA & 1.3 & $\begin{array}{l}\text { ARF3 (ETT) encodes a protein with homology to DNA-binding proteins which bind to } \\
\text { AuxREs }\end{array}$ \\
\hline AT2G47260 & IAA & 1.9 & WRKY23: Encodes a member of WRKY Transcription Factor \\
\hline AT3G11580 & IAA & 1.6 & DNA-binding protein, putative \\
\hline AT3G16500 & IAA & 1.8 & IAA26 (PAP1) phytochrome-associated protein 1 \\
\hline AT3G23250 & IAA & 1.8 & MYB15: Member of the R2R3 factor gene family \\
\hline AT4G02220 & IAA & 1.2 & Programmed cell death 2 C-terminal domain-containing protein \\
\hline AT4G21550 & IAA & 1.4 & VAL3: Symbols: VAL3 |VAL3 (VP1/ABI3-LIKE 3); transcription factor \\
\hline AT5G60450 & IAA & 0.8 & ARF4: member of the ARF family of transcription factors which mediate auxin responses \\
\hline \multicolumn{4}{|c|}{ SECONDARY METAB. } \\
\hline AT5G01210 & $\begin{array}{l}\text { ACC, } \\
\text { IAA }\end{array}$ & 2.1 & Transferase family protein \\
\hline \multicolumn{4}{|l|}{ SIGNALING } \\
\hline AT1G35140 & IAA & 2.8 & PHI-1 \\
\hline AT1G76650 & IAA & 1.3 & CML38: calcium-binding EF hand family protein \\
\hline AT2G25790 & IAA & 1.3 & Leucine-rich repeat transmembrane protein kinase \\
\hline AT2G30060 & IAA & 0.9 & Ran-binding protein 1b \\
\hline AT4G08950 & IAA & 3.8 & EXO: EXORDIUM \\
\hline AT4G28490 & IAA & 1.9 & HAE: member of Receptor kinase-like protein family \\
\hline AT5G05160 & IAA & 1.1 & RUL1: leucine-rich repeat transmembrane protein kinase \\
\hline AT5G12940 & IAA & 1.1 & Leucine-rich repeat family protein \\
\hline AT5G37770 & IAA & 2.0 & TCH2: Encodes a protein with $40 \%$ similarity to calmodulin \\
\hline \multicolumn{4}{|l|}{ STRESS } \\
\hline AT2G42530 & ACC & 1.8 & COR15B: COLD REGULATED 15B \\
\hline AT5G64900 & IAA & 1.4 & PROPEP1: Encodes a putative 92-aa protein that is the precursor of AtPep1 \\
\hline
\end{tabular}

\begin{tabular}{|c|c|c|c|}
\hline \multicolumn{4}{|r|}{ Giant cells 3 dpi } \\
\hline \multicolumn{4}{|l|}{ CELL WALL } \\
\hline AT4G25810 & IAA & 1.1 & XTR6: xyloglucan endotransglycosylase-related protein \\
\hline \multicolumn{4}{|c|}{ HORMONE METABOLISM } \\
\hline AT3G23150 & ACC & 2.1 & ETR2: Involved in ethylene perception in Arabidopsis \\
\hline AT4G20880 & ACC & 2.4 & Ethylene-responsive nuclear protein/ethylene-regulated nuclear protein \\
\hline AT2G23170 & IAA & 1.0 & GH3.3: IAA-amido synthase that conjugates Asp and other amino acids to auxin in vitro \\
\hline AT3G50660 & IAA & 1.0 & $\begin{array}{l}\text { DWF4: hydroxylase whose reaction is a rate-limiting step in brassinosteroid biosynthetic } \\
\text { pathway }\end{array}$ \\
\hline AT4G27260 & IAA & 0.8 & WES1: IAA-amido synthase that conjugates Asp and other amino acids to auxin in vitro \\
\hline AT4G39400 & IAA & 1.4 & BRI1: plasma membrane localized leucine-rich repeat receptor kinase \\
\hline AT5G25190 & $\begin{array}{l}\text { IAA, } \\
\text { ACC }\end{array}$ & 3.2 & $\begin{array}{l}\text { ESE3: encodes a member of the ERF (ethylene response factor) subfamily B-6 of } \\
\text { ERF/AP2 family }\end{array}$ \\
\hline \multicolumn{4}{|c|}{ LIPID METABOLISM } \\
\hline AT4G12110 & IAA & 1.9 & SM01-1: Encodes a member of the SMO1 family of sterol 4alpha-methyl oxidases \\
\hline \multicolumn{4}{|c|}{ METAL HANDLING } \\
\hline AT3G24450 & IAA & 1.8 & Copper-binding family protein \\
\hline \multicolumn{4}{|c|}{ NOT ASSIGNED } \\
\hline AT4G33560 & ACC & 2.3 & Unknown protein \\
\hline AT2G39370 & IAA & 2.9 & MAKR4: unknown protein \\
\hline \multicolumn{4}{|c|}{ POLYAMINE METABOLISM } \\
\hline AT5G19530 & IAA & 1.8 & ACL5: Encodes a spermine synthase \\
\hline \multicolumn{4}{|l|}{ PROTEIN } \\
\hline AT3G61160 & IAA & 1.8 & Shaggy-related protein kinase beta/ASK-beta (ASK2) \\
\hline AT3G27580 & $\begin{array}{l}\text { IAA, } \\
\text { ACC }\end{array}$ & 2.5 & ATPK7: a member of a subfamily of Ser/Thr PKs \\
\hline
\end{tabular}


Giant cells 3 dpi

\begin{tabular}{llll}
\hline $\begin{array}{l}\text { REDOX } \\
\text { AT2G16060 }\end{array}$ & ACC & 2.4 & HB1: Encodes a class 1 non-symbiotic hemoglobin \\
RNA & IAA & 1.6 & ARF19: auxin response factor \\
AT1G19220 & IAA & 4.1 & MP: Encodes a transcription factor (IAA24) \\
AT1G19850 & IAA & 1.2 & IAA8: IAA8 (IAA8) gene is auxin inducible \\
AT2G22670 & IAA & 2.5 & LBD41: LOB DOMAIN-CONTAINING PROTEIN 41 \\
AT3G02550 & IAA & 4.3 & HAT1: Encodes homeobox protein HAT1 \\
AT4G17460 & IAA & 1.0 & BEE2: BR Enhanced Expression 2 \\
AT4G36540 & IAA & 2.7 & HAT2: homeobox-leucine zipper genes induced by auxin \\
AT5G47370 & IAA & 1.1 & HB5: class I HDZip (homeodomain-leucine zipper) protein \\
AT5G65310 & IAA & 1.4 & PIP5K1: Type I phosphatidylinositol-4-phosphate 5-kinase \\
SIGNALING & IAA & 1.8 & Leucine-rich repeat transmembrane protein kinase \\
AT1G21980 & IAA & 1.1 & Leucine-rich repeat transmembrane protein kinase \\
AT1G68400 & & & \\
AT2G25790 & &
\end{tabular}

Third column shows the Log2 value for each gene in syncytia or GCs.

V. faba (Dibley et al., 2009), ethylene is proposed to participate in a signaling pathway initiating TCs morphology. Similarly to the auxin responsive genes induced in the NFC transcriptomes, some genes involved in ethylene perception, transduction, and responses are also up-regulated in GCs (Table 1; ETR2, ESE3). Ethylene responsive genes were over-represented among the 310 up-regulated genes in GCs, relative to the total number of hormone responsive genes in Nemhauser et al. (2006), Cabrera et al. (2013). ETR2 induction coincides with the presence of other ethylene receptors (as ETR1) in developing TCs from barley and rice endosperm (Thiel et al., 2012b). The ethylene precursor 1aminocyclopropane-1-carboxylic acid (ACC) directly enhanced TC formation in root epidermal cells of tomato (Schikora and Schmidt, 2002) and adaxial epidermal cells of $V$. faba cotyledons (Dibley et al., 2009). Consistently, a pool of genes encoding proteins related with ethylene synthesis like two ACC oxidases (Table 1), are induced in the transcriptome of microaspirated syncytia. Functional analysis of the Arabidopsis ethylene overproducing mutants eto 2 and eto 3 resulted in hyper-susceptibility to cyst nematodes (Goverse et al., 2000; Wubben et al., 2001). Interestingly, ethylene overproduction in eto 2 mutants stimulated the formation of CIs or protuberances in syncytia along the vascular tissue, at late infection stages (Goverse et al., 2000), providing a direct evidence for a putative role of ethylene in the stimulation of syncytia TCs characteristics. Accordingly, functional analysis of Arabidopsis mutants compromised in several steps of the signaling cascade leading to activation of ethylene responsive genes, as those altered in ethylene-insensitive mutants (etr1-1, ein2-1, ein3-1, eir1-1, and axr2), were less susceptible to H. schachtii (Wubben et al., 2001). Hence, several ACC synthase coding genes were induced at early infection stages, increasing and reaching a maximum at $20 \mathrm{dpi}$ in soybean infected with H. glycines (Tucker et al., 2010). Strikingly, ethylene production upon nematode infection has been long known in tomato infected with RKNs (M. Javanica), with a peak at medium infection stages (4-16 dpi; Glazer et al., 1983), similar to several dicotyledonous species (Glazer et al., 1985). However, not much is known on the behavior of ethylene-related mutants infected with RKNs. Experiments on Lotus japonica expressing ETR-1 were not conclusive of its putative role on RKN infection (Lohar and Bird, 2003). Undoubtedly, analysis are still lacking on the morphologic characteristics of developed syncytia in loss of function mutants of genes related to ethylene transduction pathways that could confirm their role on the induction of syncytia TCs characteristics, such us the presence of CI. Regarding RKNs, virtually no data on the TCs features of GCs in ethylene mutants are still available.

\section{TWO-COMPONENT SIGNALING SYSTEMS AND REACTIVE OXYGEN SPECIES AS INDUCERS OF TC IDENTITY IN NFCs}

Recently, Thiel et al. (2012b) suggested a role for a twocomponent signaling system (2CS) in cellularization and differentiation of barley endosperm TCs, possibly coupled to hormonal regulation by abscisic acid and ethylene. In plants, 2CSs require a hybrid histidine kinase (HK; located in the plasma membrane) with both histidine kinase and receiver domains, a histidinecontaining phosphotransfer protein $(\mathrm{HPt})$, and a response regulator that mediates downstream signaling through phosphorylation. In Arabidopsis, proteins with significant sequence similarities to all elements of the 2CSs have been identified (reviewed in Schaller et al., 2008). We have searched for genes encoding those components in the early GCs and syncytia transcriptomes (Szakasits et al., 2009; Barcala et al., 2010; Table S1). In Arabidopsis, genes encoding $8 \mathrm{HK}$ and $9 \mathrm{HK}$-like proteins (HKL) have been identified and 2 of them are up-regulated in GCs (ETR2) or syncytia $(P D K)$. However, most HKs and HKLs are down-regulated in NFCs. ETR2, HK2, HK3, ERS1, and PHYA are down-regulated in syncytia and HK1 and CKI1 in GCs (Cabrera et al., 2013; Table S1). Moreover, the two upregulated genes in NFCs are HKLs that lack residues essential to histidine kinase activity. The Arabidopsis genome encodes five $\mathrm{HPt}$ proteins $(A H P 1-5)$ that act as signaling intermediates 
between HKs and response regulators. From them, AHP3 is upregulated in syncytia while $A H P 1$ is down-regulated, and the rest of the genes are not differentially expressed in the transcriptome of micro-dissected GCs and syncytia (Barcala et al., 2010; Cabrera et al., 2013; Table S1). The last components of the system are the response regulators, with 33 genes identified in the Arabidopsis genome (23 response regulators and 10 pseudo-response regulators; Schaller et al., 2008), most of them down-regulated as well in NFCs (only ARR7 and RR14 are up-regulated in syncytia; Cabrera et al., 2013; Table S1). Thus, the transcriptomic evidence at early differentiation stages of syncytia and GCs suggests that genes involved in 2CSs do not contribute substantially to the differential gene expression observed in NFCs. Thus, 2CSs are not likely participating in the first signaling steps involved in the acquisition of TCs identify in NFCs.

Recently, it has been shown that $\mathrm{H}_{2} \mathrm{O}_{2}$ functions downstream of ethylene to activate cell wall biosynthesis and direct polarized deposition of a uniform wall on which CIs formed in TCs of $V$. faba cotyledons (Andriunas et al., 2012). The presence of a $\mathrm{H}_{2} \mathrm{O}_{2}$-generating mechanism dependent upon NADPH oxidase (NOX) activity was suggested (Andriunas et al., 2012). From the $10 \mathrm{RBOH}$ genes encoding the catalytic subunit of NOX in Arabidopsis (reviewed in Sagi and Fluhr, 2006), 7 are down-regulated in syncytia, and none of them are differentially expressed in GCs (Cabrera et al., 2013). Additionally, defenserelated genes described as related to TCs development, as in endosperm TCs where the ethylene response is possibly coupled to activated defense mechanisms (Thiel et al., 2008), are not abundant in NFCs. On the contrary, a general repression of plant defenses is obvious from the transcriptomes of early developing syncytia in Arabidopsis, where more than 35 peroxidases were repressed (Szakasits et al., 2009). Similarly, in early developing GCs of Arabidopsis and tomato not only peroxidases, but many genes from the secondary metabolism related to plant defenses were also down-regulated at 3 dpi (Barcala et al., 2010; Portillo et al., 2013). All these data suggest that active oxygen species such as $\mathrm{H}_{2} \mathrm{O}_{2}$ very unlikely function as early inducing signals for TCs identity of NFCs coupled to hormone signaling. However, it is important to point that we cannot discard the possibility of the activation of an oxidative burst in medium-late stages of NFCs development that might be participating in this process.

\section{FINAL REMARKS}

It is interesting to point that many genes induced in early differentiating NFCs correspond to typical categories of downstream regulated genes that might participate in CIs formation, as those involved in vesicle trafficking, cell wall biogenesis, cell shape control and expansion, or nutrient transport, also induced in cells undergoing differentiation into TCs (Thiel et al., 2008, 2012a; Dibley et al., 2009; Xiong et al., 2011). Many other downstream genes are also induced in NFCs contributing to their development or maintenance (reviewed in Kyndt et al., 2013). Genes associated to changes in the cytoskeleton include those encoding tubulins, actins, microtubule-binding proteins, as the IAA-induced ATG8G (Table 1) or AtFH6, a formin encoding gene that regulates polarized growth by controlling the assembly of actin cables in Arabidopsis GCs (Favery et al., 2004). However, no functions directly associated to the TCs characteristics of NFCs have been yet described for those genes in NFCs (Kyndt et al., 2013). Other genes possibly related to active nutrient uptake into syncytia and GCs are also up-regulated by either auxin (NRAMP3), ethylene (AAP3), or both (ABCG1; Table 1). However, functional studies of these genes in NFCs are very scarce (reviewed in Kyndt et al., 2013). In addition, genes encoding cell wall modifying enzymes as pectin methylesterases, expansins, xyloglucan endotransglycosylases (EXP4, XTR6, PME1, XTR6), all induced by auxin, were also induced in NFCs (Table 1). Interestingly, the most clarifying study of a functional implication in TCs characteristic of NFCs, as the CIs formation, comes from the analysis of UDP-glucose dehydrogenase (UGD) coding genes. UGDs act through oxidation of UDP-glucose producing several cell wall polysaccharides. UGD2 and UGD3 are necessary for the production of CIs in syncytia and loss of function in double mutants severely affected nematode development (Siddique et al., 2012).

In conclusion, although genes encoding proteins with similar functions are differentially expressed in differentiating NFCs and typical TCs, a clear knowledge of their implication, either upstream or downstream, in the signaling cascades leading to TCs characteristics of NFCs is still lacking. Further research will probably elucidate the contribution of signals such as hormones to those differentiation events in NFCs.

\section{ACKNOWLEDGMENTS}

This work was supported by the Spanish Government (AGL201017388 to Carolina Escobar, CSD2007-057 to Carmen Fenoll) and the Castilla-La Mancha Government (PCI08-0074-0294 to Carmen Fenoll and Carolina Escobar). Javier Cabrera was supported by a fellowship from the Ministry of Education, Spain.

\section{SUPPLEMENTARY MATERIAL}

The Supplementary Material for this article can be found online at: http://www.frontiersin.org/journal/10.3389/fpls. 2014.00107/abstract

\section{REFERENCES}

Andriunas, F. A., Zhang, H.-M., Xia, X., Offler, C. E., McCurdy, D. W., and Patrick, J.W. (2012). Reactive oxygen species form part of a regulatory pathway initiating trans-differentiation of epidermal transfer cells in Vicia faba cotyledons. J. Exp. Bot. 63, 3617-3629. doi: 10.1093/jxb/ers029

Barcala, M., Garcia, A., Cabrera, J., Casson, S., Lindsey, K., Favery, B., et al. (2010). Early transcriptomic events in microdissected Arabidopsis nematodeinduced giant cells. Plant J. 61, 698-712. doi: 10.1111/j.1365-313X.2009. 04098.x

Barrero, C., Royo, J., Grijota-Martinez, C., Faye, C., Paul, W., Sanz, S., et al. (2009). The promoter of ZmMRP-1, a maize transfer cell-specific transcriptional activator, is induced at solute exchange surfaces and responds to transport demands. Planta 229, 235-247. doi: 10.1007/s00425-0080823-0

Brady, S. M., Orlando, D. A., Lee, J.-Y., Wang, J. Y., Koch, J., Dinneny, J. R., et al. (2007). A high-resolution root spatiotemporal map reveals dominant expression patterns. Science 318, 801-806. doi: 10.1126/science.1146265

Cabrera, J., Bustos, R., Favery, B., Fenoll, C., and Escobar, C. (2013). NEMATIC: a simple and versatile tool for the in silico analysis of plant-nematode interactions. Mol. Plant Pathol. doi: 10.1111/mpp.12114. [Epub ahead of print]. 
De Meutter, J., Tytgat, T., Prinsen, E., Gheysen, G., Van Onckelen, H., and Gheysen, G. (2005). Production of auxin and related compounds by the plant parasitic nematodes Heterodera schachtii and Meloidogyne incognita. Commun. Agric. Appl. Biol. Sci. 70, 51-60.

Dibley, S. J., Zhou, Y., Andriunas, F. A., Talbot, M. J., Offler, C. E., Patrick, J. W., et al. (2009). Early gene expression programs accompanying trans-differentiation of epidermal cells of Vicia faba cotyledons into transfer cells. New Phytol. 182, 863-877. doi: 10.1111/j.1469-8137.2009.02822.x

Favery, B., Chelysheva, L. A., Lebris, M., Jammes, F., Marmagne, A., De Almeida-Engler, J., et al. (2004). Arabidopsis formin AtFH6 is a plasma membrane-associated protein upregulated in giant cells induced by parasitic nematodes. Plant Cell Online 16, 2529-2540. doi: 10.1105/tpc.104. 024372

Glazer, L., Orion, D., and Apelbaum, S. (1983). Interrelationships between ethylene production, gall formation, and root-knot nematode development in tomato plants infected with Meloidogyne javanica. J. Nematol. 15, 539-544.

Glazer, L., Orion, D., and Apelbaum, S. (1985). Ethylene production by Meloidogyne spp.-infected plants. J. Nematol. 17, 61-63.

Gomez, E., Royo, J., Guo, Y., Thompson, R., and Hueros, G. (2002). Establishment of cereal endosperm expression domains: identification and properties of a maize transfer cell-specific transcription factor, ZmMRP-1. Plant Cell 14, 599-610. doi: 10.1105/tpc.010365

Goverse, A., Overmars, H., Engelbertink, J., Schots, A., Bakker, J., and Helder, J. (2000). Both induction and morphogenesis of cyst nematode feeding cells are mediated by auxin. Mol. Plant Microbe Interact. 13, 1121-1129. doi: 10.1094/MPMI.2000.13.10.1121

Grunewald, W., Van Noorden, G., Van Isterdael, G., Beeckman, T., Gheysen, G., and Mathesius, U. (2009). Manipulation of auxin transport in plant roots during Rhizobium symbiosis and nematode parasitism. Plant Cell 21, 2553-2562. doi: 10.1105/tpc.109.069617

Hofmann, J., El Ashry Ael, N., Anwar, S., Erban, A., Kopka, J., and Grundler, F. (2010). Metabolic profiling reveals local and systemic responses of host plants to nematode parasitism. Plant J. 62, 1058-1071. doi: 10.1111/j.1365313X.2010.04217.x

Hofmann, J., Wieczorek, K., Blochl, A., and Grundler, F. M. (2007). Sucrose supply to nematode-induced syncytia depends on the apoplastic and symplastic pathways. J. Exp. Bot. 58, 1591-1601. doi: 10.1093/jxb/erl285

Hoth, S., Stadler, R., Sauer, N., and Hammes, U. Z. (2008). Differential vascularization of nematode-induced feeding sites. Proc. Natl. Acad. Sci. U.S.A. 105, 12617-12622. doi: 10.1073/pnas.0803835105

Hutangura, P., Mathesius, U., Jones, M. G. K., and Rolfe, B. G. (1999). Auxin induction is a trigger for root gall formation caused by root-knot nematodes in white clover and is associated with the activation of the flavonoid pathway. Funct. Plant Biol. 26, 221-231. doi: 10.1071/PP98157

Jones, J. T., Furlanetto, C., Bakker, E., Banks, B., Blok, V., Chen, Q., et al. (2003). Characterization of a chorismate mutase from the potato cyst nematode Globodera pallida. Mol. Plant Pathol. 4, 43-50. doi: 10.1046/j.13643703.2003.00140.x

Jones, J. T., Furlanetto, C., and Phillips, M. S. (2007). The role of flavonoids produced in response to cyst nematode infection of Arabidopsis thaliana. Nematology 9, 671-677. doi: 10.1163/156854107782024875

Jones, M. G. K., and Dropkin, V. H. (1976). Scanning electron microscopy in nematode-induced giant transfer cells. Cytobios 15, 149-161.

Jones, M. G. K., and Goto, D. B. (2011). "Root-knot nematodes and giant cells," in Genomics and Molecular Genetics of Plant-Nematode Interactions, eds J. Jones, G. Gheysen, and C. Fenoll (Dordrecht: Springer), 83-102. doi: 10.1007/978-94007-0434-3_5

Karczmarek, A., Overmars, H., Helder, J., and Goverse, A. (2004). Feeding cell development by cyst and root-knot nematodes involves a similar early, local and transient activation of a specific auxin-inducible promoter element. Mol. Plant Pathol. 5, 343-346. doi: 10.1111/j.1364-3703.2004.00230.x

Kyndt, T., Vieira, P., Gheysen, G., and De Almeida-Engler, J. (2013). Nematode feeding sites: unique organs in plant roots. Planta 238, 807-818. doi: 10.1007/s00425-013-1923-Z

Lee, C., Chronis, D., Kenning, C., Peret, B., Hewezi, T., Davis, E. L., et al. (2011). The novel cyst nematode effector protein 19C07 interacts with the Arabidopsis auxin influx transporter LAX3 to control feeding site development. Plant Physiol. 155, 866-880. doi: 10.1104/pp.110.167197
Lohar, D. P., and Bird, D. M. (2003). Lotus japonicus: a new model to study root-parasitic nematodes. Plant Cell Physiol. 44, 1176-1184. doi: 10.1093/pcp/ pcg146

Nakazawa, M., Yabe, N., Ichikawa, T., Yamamoto, Y. Y., Yoshizumi, T., Hasunuma K., et al. (2001). DFL1, an auxin-responsive GH3 gene homologue, negatively regulates shoot cell elongation and lateral root formation, and positively regulates the light response of hypocotyl length. Plant J. 25, 213-221. doi: 10.1111/j.1365-313X.2001.00957.x

Nemhauser, J. L., Hong, F., and Chory, J. (2006). Different plant hormones regulate similar processes through largely nonoverlapping transcriptional responses. Cell 126, 467-475. doi: 10.1016/j.cell.2006.05.050

Portillo, M., Cabrera, J., Lindsey, K., Topping, J., Andres, M. F., Emiliozzi, M., et al. (2013). Distinct and conserved transcriptomic changes during nematodeinduced giant cell development in tomato compared with Arabidopsis: a functional role for gene repression. New Phytol. 197, 1276-1290. doi: $10.1111 / \mathrm{nph} .12121$

Sagi, M., and Fluhr, R. (2006). Production of reactive oxygen species by plant NADPH oxidases. Plant Physiol. 141, 336-340. doi: 10.1104/pp.106.078089

Schaller, G. E., Kieber, J. J., and Shiu, S.-H. (2008). Two-component signaling elements and histidyl-aspartyl phosphorelays. Arabidopsis Book 6:e0112. doi: 10.1199/tab.0112

Schikora, A., and Schmidt, W. (2002). Formation of transfer cells and H(+)-ATPase expression in tomato roots under $\mathrm{P}$ and Fe deficiency. Planta 215, 304-311. doi: 10.1007/s00425-002-0738-0

Siddique, S., Sobczak, M., Tenhaken, R., Grundler, F. M. W., and Bohlmann, H. (2012). Cell wall ingrowths in nematode induced syncytia require UGD2 and UGD3. PLoS ONE 7:e41515. doi: 10.1371/journal.pone.0041515

Sobczak, M., and Golinowski, W. (2009). "Structure of cyst nematode feeding sites," in Genomics and Molecular Genetics of Plant-Nematode Interactions, eds J. Jones, G. Gheysen, and C. Fenoll (Dordrecht: Springer), 153-188.

Sobczak, M., and Golinowski, W. (2011). "Cyst nematodes and syncytia," in Genomics and Molecular Genetics of Plant-Nematode Interactions, eds J. Jones, G. Gheysen, and C. Fenoll (Dordrecht: Springer), 83-102.

Szakasits, D., Heinen, P., Wieczorek, K., Hofmann, J., Wagner, F., Kreil, D. P., et al. (2009). The transcriptome of syncytia induced by the cyst nematode Heterodera schachtii in Arabidopsis roots. Plant J. 57, 771-784. doi: 10.1111/j.1365-313X.2008.03727.x

Thiel, J., Hollmann, J., Rutten, T., Weber, H., Scholz, U., and Weschke, W. (2012b). 454 Transcriptome sequencing suggests a role for two-component signalling in cellularization and differentiation of barley endosperm transfer cells. PLoS ONE 7:e41867. doi: 10.1371/journal.pone.0041867

Thiel, J., Riewe, D., Rutten, T., Melzer, M., Friedel, S., Bollenbeck, F., et al. (2012a). Differentiation of endosperm transfer cells of barley: a comprehensive analysis at the micro-scale. Plant J. 71, 639-655. doi: 10.1111/j.1365-313X.2012.05018.x

Thiel, J., Weier, D., Sreenivasulu, N., Strickert, M., Weichert, N., Melzer, M., et al. (2008). Different hormonal regulation of cellular differentiation and function in nucellar projection and endosperm transfer cells: a microdissection-based transcriptome study of young barley grains. Plant Physiol. 148, 1436-1452. doi: 10.1104/pp.108.127001

Thimm, O., Blasing, O., Gibon, Y., Nagel, A., Meyer, S., Kruger, P., et al. (2004). MAPMAN: a user-driven tool to display genomics data sets onto diagrams of metabolic pathways and other biological processes. Plant J. 37, 914-939. doi: 10.1111/j.1365-313X.2004.02016.x

Tucker, M. L., Xue, P., and Yang, R. (2010). 1-Aminocyclopropane-1-carboxylic acid (ACC) concentration and ACC synthase expression in soybean roots, root tips, and soybean cyst nematode (Heterodera glycines)-infected roots. J. Exp. Bot. 61, 463-472. doi: 10.1093/jxb/erp317

Wasson, A. P., Ramsay, K., Jones, M. G., and Mathesius, U. (2009). Differing requirements for flavonoids during the formation of lateral roots, nodules and root knot nematode galls in Medicago truncatula. New Phytol. 183, 167-179. doi: 10.1111/j.1469-8137.2009.02850.x

Wubben, M. J. E., Su, H., Rodermel, S. R., and Baum, T. J. (2001). Susceptibility to the sugar beet cyst nematode is modulated by ethylene signal transduction in Arabidopsis thaliana. Mol. Plant Microbe Interact. 14, 1206-1212. doi: 10.1094/MPMI.2001.14.10.1206

Xiong, Y., Li, Q.-B., Kang, B.-H., and Chourey, P. (2011). Discovery of genes expressed in basal endosperm transfer cells in maize using 454 transcriptome sequencing. Plant Mol. Biol. Rep. 29, 835-847. doi: 10.1007/s11105-011-0291-8 
Zhou, Y., Andriunas, F., Offler, C. E., McCurdy, D. W., and Patrick, J. W. (2010). An epidermal-specific ethylene signal cascade regulates trans-differentiation of transfer cells in Vicia faba cotyledons. New Phytol. 185, 931-943. doi: 10.1111/j.1469-8137.2009. 03136.x

Conflict of Interest Statement: The authors declare that the research was conducted in the absence of any commercial or financial relationships that could be construed as a potential conflict of interest.

Received: 15 January 2014; accepted: 06 March 2014; published online: 24 March 2014.
Citation: Cabrera J, Barcala M, Fenoll C and Escobar C (2014) Transcriptomic signatures of transfer cells in early developing nematode feeding cells of Arabidopsis focused on auxin and ethylene signaling. Front. Plant Sci. 5:107. doi: 10.3389/fpls.2014.00107 This article was submitted to Plant Physiology, a section of the journal Frontiers in Plant Science.

Copyright (๑) 2014 Cabrera, Barcala, Fenoll and Escobar. This is an open-access article distributed under the terms of the Creative Commons Attribution License (CC BY). The use, distribution or reproduction in other forums is permitted, provided the original author(s) or licensor are credited and that the original publication in this journal is cited, in accordance with accepted academic practice. No use, distribution or reproduction is permitted which does not comply with these terms. 